\title{
COMPLEX POTENTIODYNAMIC RESPONSE OF SILVER IN ALKALINE ELECTROLYTES IN THE POTENTIAL RANGE OF THE $\mathrm{Ag} / \mathrm{Ag}_{2} \mathrm{O}$ COUPLE
}

\author{
M. LOPEZ TEIJELO *, J.R. VILCHE and A.J. ARVIA \\ Irusticulo de Investigaciones Fisicaquimicas Teónicas y Aplicadas, Divisiön Electraquimica, Sucursal 4. Casılla \\ de Correo 16, (1900) La Plata (Argentina)
}

(Received 28th April 1981; in revised form I6th June 1981)

\section{ABSTRACT}

The potentiodynamic behaviour of $\mathrm{Ag}$ in $0.1 \mathrm{M} \mathrm{NaOH}$ in the potential range of $\mathrm{Ag}_{2} \mathrm{O}$ electroformation is investigated through the application of different potential/time perturbation programmes. The splitting of the electroreduction profile which is produced under well-defined perturbation conditions and the shift of the $\mathrm{Ag}_{2} \mathrm{O}$ electroreduction $E / i$ profile under a constant charge condition, suggest that ageing-type processes are involved in the overall electrochemical reaction. These processes are related to a probable dehydration of the $\mathrm{Ag}_{2} \mathrm{O}$ multilayer.

\section{INTRODUCTION}

Since the work of Luther and Pokorny on the anodic oxidation of Ag in alkaline electrolytes [1] many investigations have been published on the subject, but, as deduced from the various reviews written on the electrochemical behaviour of silver and its oxides [2-6], there are several important questions without an adequate answer, specially conceming the mechanism of the electrochemical reaction, the structure of the different silver oxides and hydroxides and the possible contribution of chemical transformation in the overall process.

The potentiodynamic response of the $\mathrm{Ag}$ /alkaline solution interphase under a repetitive potential cycling generally show, four anodic current peaks (I, II, III and IV) during the positive-going potential scan, and during the reverse scan two cathodic current peaks (V and VI) (Fig. 1). All these peaks appear in a potential range from $0.2 \mathrm{~V}$ to $1.0 \mathrm{~V}$ preceding the $O_{2}$. evolution reaction [4-10]. There is general agreement in the literature that the anodic peaks I, II and III are related to the electroformation of $\mathrm{Ag}(\mathrm{I})$-oxygen-containing species and peak IV is related to the electroformation of AgO. The corresponding complementary electroreduction current peaks are found in the cathodic scan at potentials which are appreciably more negative that those of the corresponding anodic ones. Other fine structure details in the voltammogram are still not definitely settled. From poteritiodynamic

\footnotetext{
- Present address: Departamento de Fisicoquimica, Universidad Nacional de Cóndoba, Córdoba,
} Argentina. 


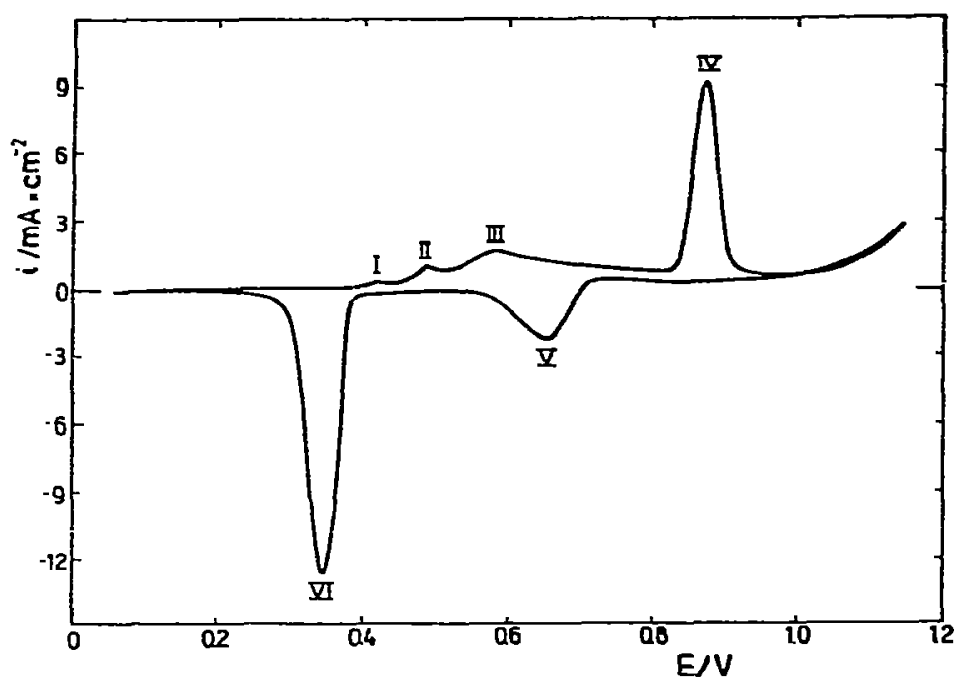

Fig. 1. Potentiodynamic $E / i$ display run at $0.01 \mathrm{~V} \mathrm{~s}^{-1}$.

data reported at present it is also concluded that in the potential range of the $\mathrm{Ag} / \mathrm{Ag}_{2} \mathrm{O}$ couple there is no ageing process $[6,9]$, as measured through the shift of the corresponding cathodic current peak, in contrast with the oxygen chemisorption on different noble metal electrodes [11-14].

The present report furnishes some new preliminary results which reveal, on the one hand, the composite structure of the anodic film electroformed on $\mathrm{Ag}$ in alkaline solutions in the potential range of the $\mathrm{Ag} / \mathrm{Ag}_{2} \mathrm{O}$ couple and, on the other, the possibility of inducing a multiplicity of electroreduction current peaks when the electrochemical interface is properly perturbed under controlled potential conditions. The latter is interpreted in terms of possible structural changes of the various species formed during the electrooxidation reaction.

\section{EXPERIMENTAL}

Potentiodynamic $E / i$ curves were obtained in a three-compartment electrolysis cell, each compartment connected through fritted glass discs and cup-type glass stopcocks lubricated with the same electrolytic solution. Specpure (Johnson Matthey Chemicals) silver working electrodes were used in the form of either fixed wires (0.5 $\mathrm{mm}$ diameter, $0.16 \mathrm{~cm}^{2}$ apparent area) or rotating discs $\left(0.063 \mathrm{~cm}^{2}\right.$ apparent area) supported with PTFE holders. The counter electrode was a large area Pt sheet previously cleaned with the usual procedures. Runs were made in $0.1 M \mathrm{NaOH}$ solutions prepared from analytical grade (p.a. Merck) reagent and triply distilled water, at $25^{\circ} \mathrm{C}$ under purified $\mathrm{N}_{2}$ gas saturation. The $\mathrm{Ag}$ electrodes were mechanically polished with $\mathbf{4 0 0}$ grit alumina-acetone suspension and then thoroughly rinsed in distilled water. Before each potentiodynamic measurement the electrode was held 
for $2 \mathrm{~min}$ in the hydrogen evolution potentiai region.

The potential of the $\mathrm{Ag} / 0.1 \mathrm{M} \mathrm{NaOH}$ interface was perturbed using single (STPS), symmetric repetitive (RTPS) and asymmetric repetitive (ATPS) triangular potential sweeps, triangularly modulated triangular potential sweeps (TMTPS) and combined potential programmes as those proposed to promote the potentiostatic and the potentiodynamic ageing effects on the electrochemically formed [15] surface species. The scheme of the complex potential/time $(E / t)$ perturbations are depicted in the same figure together with the corresponding $E / i$ display. Potentials were measured vs. a SCE, but in the text they are referred to the NHE scale.

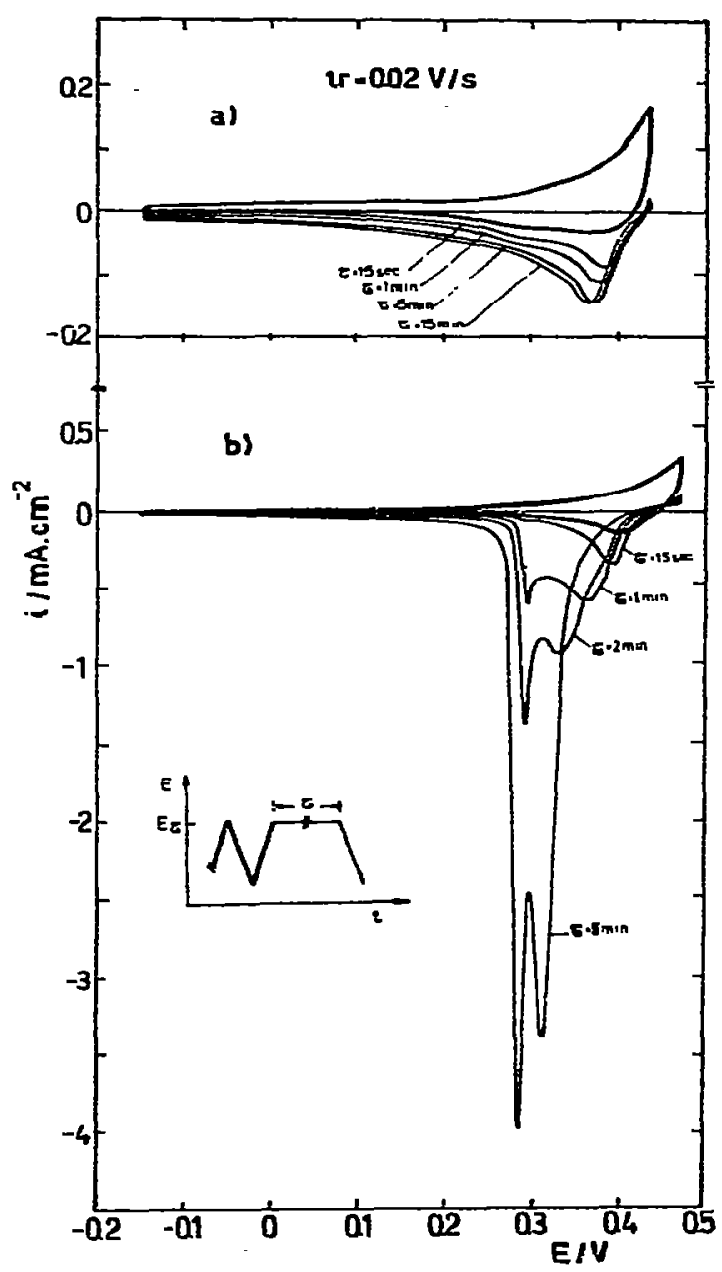

Fig. 2. Potentiodysamic $E / i$ displays obtained with the perturbation programme depicted in the figure; $y=0.02 \mathrm{~V} \mathrm{~s}^{-1} ; E_{\mathrm{sc}}=-0.15 \mathrm{~V}$. (a) $E_{\mathrm{r}}=0.44 \mathrm{~V}$; (b) $E_{\mathrm{r}}=0.48 \mathrm{~V}$. 


\section{RESULTS}

The early stages of the Ag electro-oxidation process are complex and extremely sensitive to the perturbation conditions applied to the electrode, especially when the potential sweep involves a potential holding at the anodic switching potential $\left(E_{\mathrm{s}, \mathrm{a}}\right)$ for a time $\tau$ before running the electroreduction $E / i$ profile (Fig. 2). The latter changes drastically when $E_{\mathrm{s}, \mathrm{a}}$ and $\tau$ are changed, both in the amount of electroreduction charge involved and in the shape of the whole $E / i$ contour. When $E_{\mathrm{s}, \mathrm{a}}=0.44 \mathrm{~V}$ a slight but progressive increase of the electroreduction charge is noticed as $\tau$ increases. Likewise the potential of the single electroreduction current peak moves steadily towards the negative potential side, to attain, probably, a limiting value at ca. $0.35 \mathrm{~V}$ after holding the potential at $0.44 \mathrm{~V}$ for $15 \mathrm{~min}$. Conversely, when the potential is held at $0.48 \mathrm{~V}$, the increase of the electroreduction charge with the time $\tau$ spent at $E_{\mathrm{s}, \mathrm{a}}$ is more dramatic than in the former case and the changes are even more remarkable as the electroreduction $E / i$ profile moves from a wide peak at ca. $0.4 \mathrm{~V}$

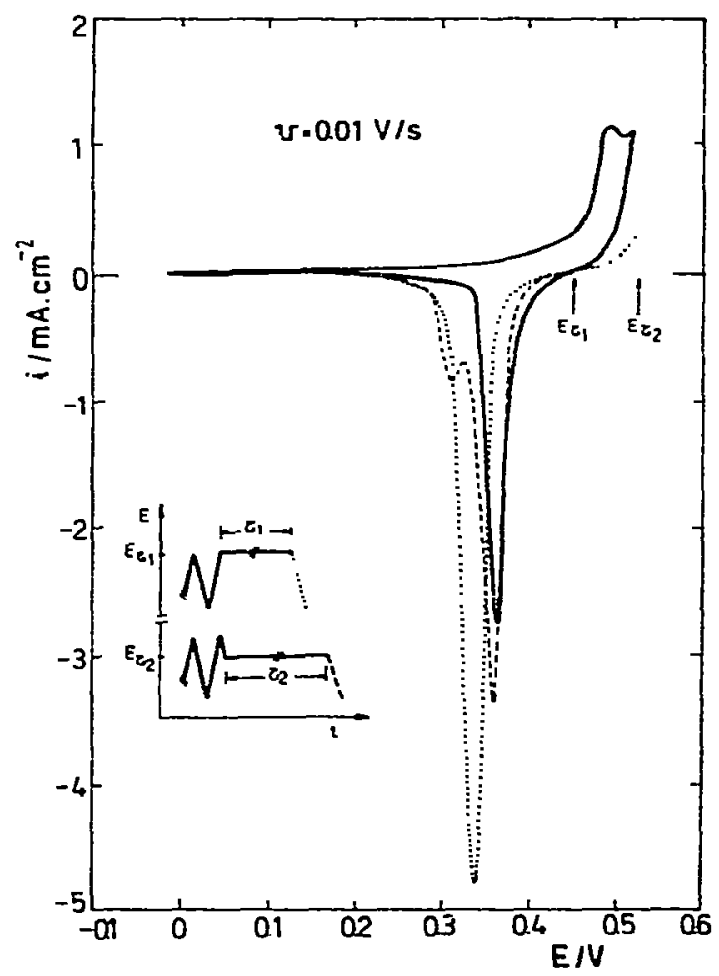

Fig. 3. Potentiodynamic $E / i$ displays obtained with the complex perturbation programme included in the figure. The full trace corresponds to the stabilized RTPS $E / i$ profile and the dashed traces correspond to negative-going potential scans after holding the potential at $E_{\mathrm{r}}, \nu=0.01 \mathrm{~V} \mathrm{~s}^{-1}$. $E_{\mathrm{s}, \mathrm{a}}=0.53 \mathrm{~V} ; E_{\mathrm{s}, \mathrm{c}}=$ $-0.02 \mathrm{~V} ; e_{r_{1}}=0.53 \mathrm{~V}, \tau_{1}=30 \mathrm{~s} ; E_{\mathrm{r}_{2}}=0.44 \mathrm{~V}, \tau_{2}=30 \mathrm{~min}$ 
recorded when $\tau \rightarrow 0$, to a doublet composed by two sharp electroreduction current peaks after $\tau=5 \mathrm{~min}$ of holding the potential at $E_{\mathrm{s}, \mathrm{a}}$. Then, the potentials of the electroreduction current peaks are very well defined at ca. $0.29 \mathrm{~V}$ and $0.32 \mathrm{~V}$ respectively. The electroreduction $E / i$ profile depicted in Fig. $2 b$ suggests the existence of a hump at ca. $0.38 \mathrm{~V}$. which is probably related to the gradual decrease of the electroreduction current peak initially recorded at ca. $0.4 \mathrm{~V}$.

The clear splitting of the electroreduction $E / i$ profile found when $E_{\tau}=0.48 \mathrm{~V}$ and $\tau=5 \mathrm{~min}$ disappears when $E_{\mathrm{s,a}}$ is increased to $0.53 \mathrm{~V}$ (Fig. 3). When the potential is held at $E_{\mathrm{r}}=0.53 \mathrm{~V}$ for $30 \mathrm{~s}$, a slight increase of the electroreduction charge is seen, but only a single cathodic current peak is recorded. On the other hand, when $E_{\tau}=0.44 \mathrm{~V}$, a potential at which the net current is zero and $\tau=30 \mathrm{~min}$, the electroreduction charge remains practically the same as before, but there is a clear splitting of the electroreduction profile.

In order to determine the existence of possible changes of the electro-oxidation product, runs were made by perturbing the electrode with the combined triangular potential sweep perturbation. The influence of the intermediate potential cycling at a constant time on the species which are produced at the early stages of Ag electrooxidation in the alkaline electrolyte depends on the cathodic switching potential $E_{s, c}^{\prime}$ (Fig- 4). When $E_{s, c}^{\prime}=0.43 \mathrm{~V}$, the immediately following negative going potential scan exhibits an accumulation of charge during the intermediate potential cycling which is deduced from the cathodic charge involved in the single and asymmetric electroreduction current peak located at ca. $0.37 \mathrm{~V}$. On the other hand, when $E_{\mathrm{s}, \mathrm{c}}^{\prime}=0.38 \mathrm{~V}$, the results are remarkably different, as there is a clear splitting of the electroreduc-

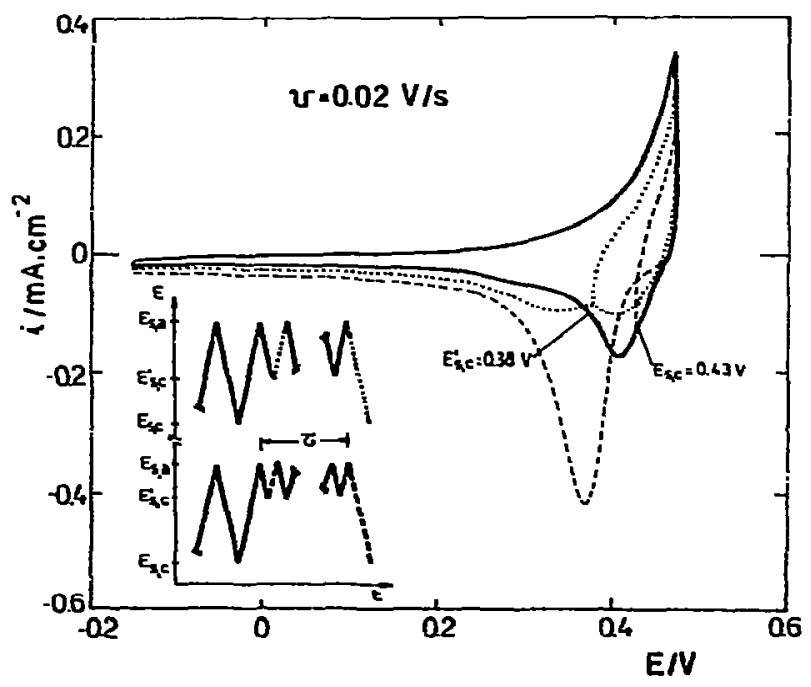

Fig. 4. Potentiodynamic $E / i$ displays obtained with the perturbation programme shown in the figure. The full trace corresponds to the stabilized RTPS $E / i$ profile and the dashed traces correspond to the potentiodynamic ageing; $\tau=10 \mathrm{~min} ; \nu=0.02 \mathrm{~V} \mathrm{~s}^{-1} . E_{\mathrm{s}, \mathrm{c}}=-0.15 \mathrm{~V} ; e_{\mathrm{s}, \mathrm{a}}=0.48 \mathrm{~V}$. 
tion current peak into two components located, respectively, at ca. $0.4 \mathrm{~V}$ and ca. $0.35 \mathrm{~V}$ without producing any appreciable change in the electroreduction charge involved. These results indicate that in the potential range up to $E_{\mathrm{s} . \mathrm{a}}=0.48 \mathrm{~V}$, i.e. in the early stages of $\mathrm{Ag}$ electro-oxidation, there are at least two different species associated with this reaction. The first species which is related to the electroreduction current peak recorded at ca. $0.4 \mathrm{~V}$ is formed initially as deduced from the conventional profile, but on perturbing the interface as indicated in Fig. 4, it undergoes a change into a second species which electroreduces in the potential range of the current peak located at $0.37 \mathrm{~V}$. A clear enhancement of the amount of the second species appears when the perturbation conditions allow the accumulation of the anodic reaction product at the interface.

The changes referred to above are even more complex when $E_{\mathrm{s}, \mathrm{a}}$ is extended to higher potentials covering the potential range of the anodic current peaks I, II and III, and the potential holding, before running the corresponding $E / i$ electroreduction profile, is made at an $E_{\mathrm{r}}$ value where the net current passing through the interface is practically zero, in order to avoid, during time $\tau$, an appreciable change of the overall charge influencing the potentiodynamic run (Fig. 5). Under these circumstances, when $E_{\tau}=0.45 \mathrm{~V}$, even for a $\tau$ value as large as $30 \mathrm{~min}$, no significant change is observed in the electroreduction profile, neither in charge nor in the current peak position and shape, except for a very small decrease in the peak height and a slight increase in the cathodic current on both sides of the peak base. There is, therefore, a compensating effect as far as the overall electroreduction

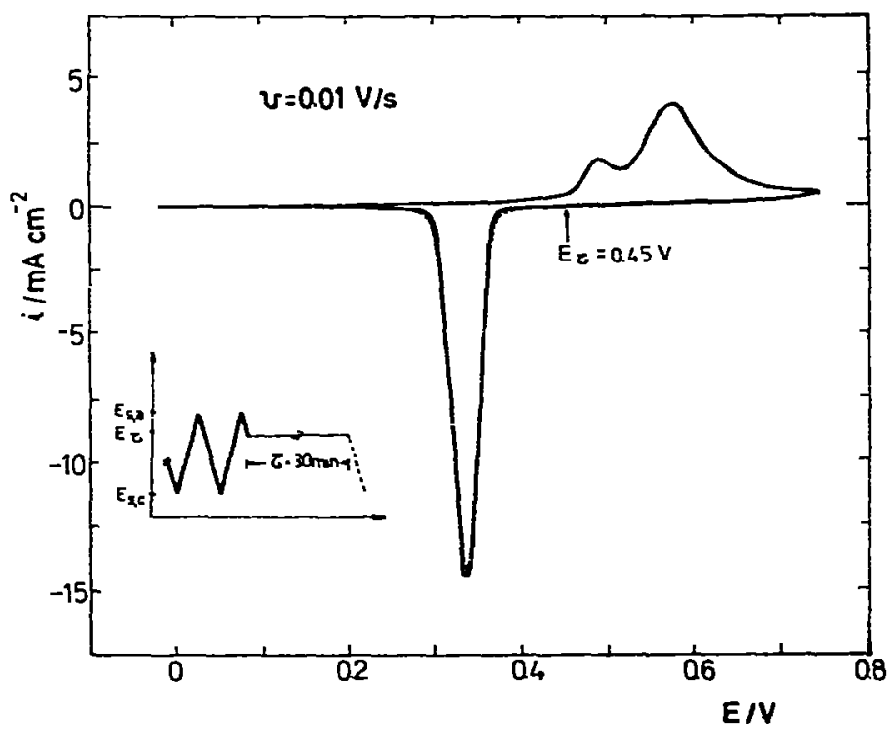

Fig. 5. Potentiodynamic $E / i$ displays obtained with the perturbation programme shown in the figure. The full trace refers to the stabilized RTPS $E / i$ profile and the dashed trace corresponds to the negative-going potential scan after holding the potential at $E_{\mathrm{r}}=0.45 \mathrm{~V}$ for $\tau=30 \mathrm{~min}$ : $\nu=0.01 \mathrm{~V} \mathrm{~s}^{-1}$ : $E_{\mathrm{s}, \mathrm{c}}=-0.02 \mathrm{~V}: E_{\mathrm{s}, \mathrm{a}}=0.74 \mathrm{~V}$. 


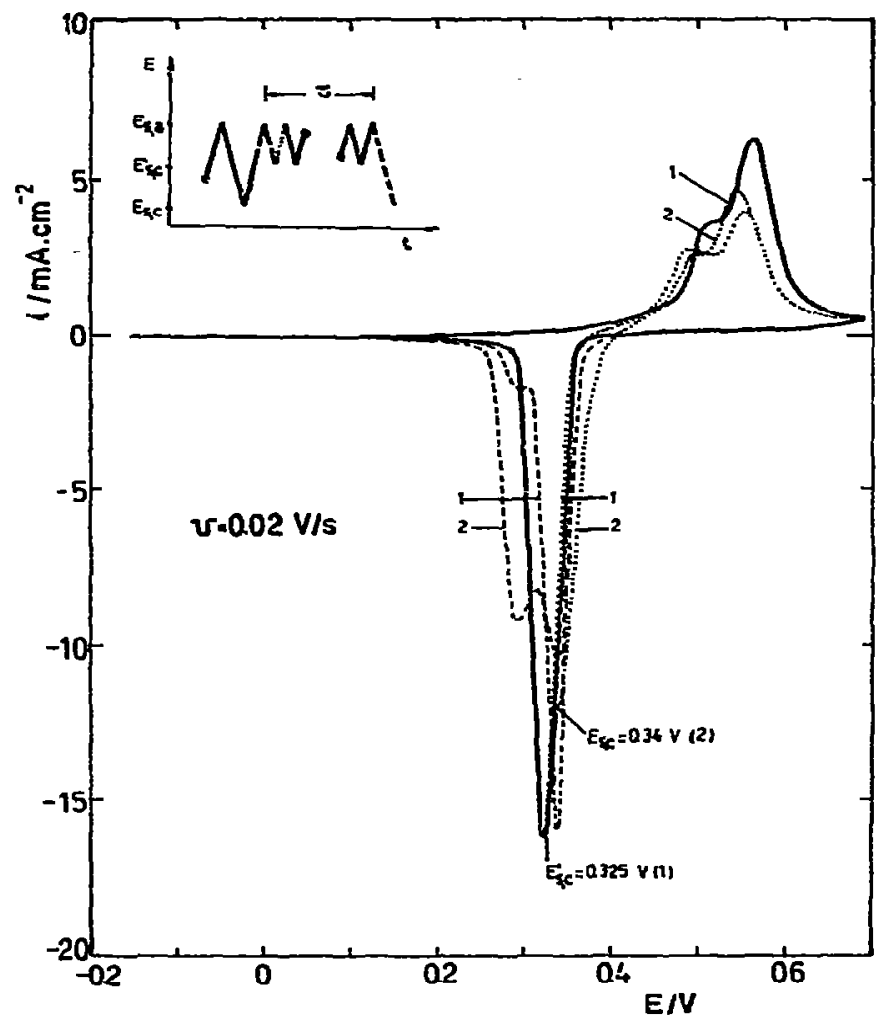

Fig. 6. Potentiodynamic $E / i$ displays obtained with the pertubation programme depicted in the figure. The full trace corresponds to the stabilized RTPS $E / i$ profile and the dashed traces correspond to the potentiodynamic ageing; $\nu=0.02 \mathrm{~V} \mathrm{~s}^{-1} ; E_{\mathrm{s}, \mathrm{c}}=-0.16 \mathrm{~V} ; E_{\mathrm{s}, \mathrm{a}}=0.69 \mathrm{~V} ; \mathrm{r}=10 \mathrm{~min}$.

charge is concerned. The use of the combined triangular potential sweep also produces in this case a significant splitting in the electroreduction profile. When the $E_{s, c}^{\prime}$ values are properly adjusted (Fig. 6), even after 10 min of potential cycling the overall cathodic charge recorded afterwards is practically the same as that exhibited in the conventional triangular potential sweep $E / i$.display. The split electroreduction profile involves two current peaks, respectively located at ca. $0.30 \mathrm{~V}$ and $0.35 \mathrm{~V}$.

Finally, when the electrode is perturbed with TMTPS at the early stage of the electro-oxidation process, the initial reaction exhibits a reversible behaviour.

\section{DISCUSSION}

When the present results are compared to those recently reported [16] for the $\mathrm{Ag} /$ alkaline solution interfaces subjected to triangular potential sweeps there is a good coincidence as far as the reversible characteristics of the early stages of the $\mathbf{A g}$ electro-oxidation is concerned, but there is a discrepancy in dealing with the 
complexity of the electrochemical reactions, as revealed through the electroreduction potentiodynamic $E / i$ profiles. From the latter one infers that the participation of processes such as those described under the name "ageing" should be considered in the overall electrochemical reactions.

The potentiodynamic $E / i$ displays of $\mathrm{Ag}$ in alkaline solutions obtained at relatively low potential sweep rates exhibit a relatively large charge and a good definition of their complex structure. On the other hand, although the potentiodynamic displays always involve a ratio of anodic to cathodic charge equal to unity, independently of the potential sweep rate and switchirg potentials used in perturbing the electrode, both the anodic and the cathodic charges decrease accordingly with the duration of the potential sweep. These results indicate the electroformation of a relatively thick film with complex structure. In any case, when the potential sweep rate is in the $0.001-0.150 \mathrm{~V} \mathrm{~s}^{-1}$ range the charge influencing both the anodic and the cathodic processes largely exceeds that expected for a single oxygen electrosorbed monolayer.

The splitting of the electroreduction profiles in the potential range of the $\mathrm{Ag}_{2} \mathrm{O}$ is an indication that the initial product undergoes a structural change into other species whose electroreduction potential is slightly different from that of the former species. Furthermore, as the structural change is also produced under the constant cathodic charge condition, it exhibits the same feature as the ageing effects already described in the electrochemical formation of adsorbed monolayers and multilayers of $\mathrm{OH}$ - and $\mathrm{O}$-containing species on different metals in aqueous electrolytes. Therefore, it can be concluded that ageing processes related to the $\mathrm{Ag} / \mathrm{Ag}_{2} \mathrm{O}$ couple are also possible in the electro-oxidation of $\mathrm{Ag}$ in the alkaline electrolyte. The potential shift promoted by the ageing process is in the order of $0.05 \mathrm{~V}$. This value, neglecting any surface activity correction, corresponds to an energy change of ca. 10 $\mathrm{kJ} \mathrm{mol}^{-1}$. This energy which coincides with the rupture of a hydrogen bond suggests that the ageing in this case could be related to a dehydration process in the film, i.e. a change in its water content. The magnitude of the ageing effect and the explanation advanced for the $\mathrm{Ag}_{2} \mathrm{O}$ film are similar to that recently reported for the open-circuit ageing of Pt(O) monolayers [12]. Unfortunately, the electrochemical method is limited in giving further information about the structure of either the unaged or the aged form of the $\mathrm{Ag}(\mathrm{I})$-oxygen-containing species.

The enhancement of the splitting of the electroreduction profile through the potentiodynamic ageing perturbation should be related to a possible surface restructuring of Ag. The possibility of a metal surface restructuring contribution is inferred from the change of the electro-oxidation profile run immediately after the electroreduction profile of the aged $\mathrm{Ag}_{2} \mathrm{O}$ species. The metal surface restructuring should assist the reaccommodation processes involving the hydration of the film-forming species and its porosity. These results and the explanation advanced are in agreement with the recently proposed complex film formation model applied to the interpretation of the ellipsometric response of the $\mathrm{Ag} / 6 \mathrm{M} \mathrm{KOH}$ interphase. The model includes the formation of six layers, namely a mass-transport boundary layer; the hydrate layer which involves colloidal or polymeric forms of oxides, hydroxides 
and anion complex and type I and iype II films [17] and the formation of secondary crystals. It also implies the time dependence of all the measured parameters, including as the most important the porosity of the hydrated layer, the onset of secondary crystal growth and the time required to reach the steady-state hydration concentration.

\section{ACKNOWLEDGEMENT}

I.N.I.F.T.A. is sponsored by the Consejo Nacional de Investigaciones Cientificas y Térnicas, the Universidad Nacional de La Plata and the Comision de Investigaciones Cientificas (Provincia de Buenos Aires). This work was partially supported by the Regional Program for the Scientific and Technological Development of the Organization of the American States. One of us (M.L.T.) thanks the University of Córdoba for leave of absence.

\section{REFERENCES}

1 R. Luther and F. Pokorny, Z. Anorg. Allg. Chem., 57 (1908) 290.

2 L. Young, Anodic Oxide Films, Academic Press, London, 1961, p. 302.

3 J.P. Hoare, The Electrochemistry of Oxygen, Interscience, New York, 1968, p. 211.

4 B.V. Tilak, R.S. Perkins, H.A. Kozlowska and B.E Conway, Electrochim. Acta, 17 (1972) 1447.

5 N.A. Shumilova and G.V. Zhutaeva in A.J. Bard (Ed.), Encyclopedia of Electrochemistry of the Elements, Vol. VII, Marcel Dekker, New York, 1978, p. 1.

6 I.M.M. Droog and F. Huisman, J. Electroanal. Chem., 115 (1980) 211.

7 P. Stonehart, Electrochim. Acta, 13 (1968) 1789, 1805.

8 J. Ambrose and R.G. Barradas, Electrochim. Acta, 19 (1964) 781.

9 J.M.M. Droog, P.T. Alderliesten and G.A. Bootsma, J. Electroanal. Chem., 99 (1979) 173.

10 G.T. Burstein and R.C. Newman, Electrochim. Acta, 25 (1980) 1009.

11 C.M. Ferro, A.J. Calandra and A.J. Arvia, J. Electroanal. Chem., 59 (1975) 239.

12 M.E Folquer, J.O. Zerbino, N.R. de Tacconi and A.J. Arvia, J. Electrochem. Soc., 126 (1979) 592.

13. R. Córdova Orellana, M.E. Martins and A.J. Arvia, Electrochim. Acta, 25 (1980) 453.

14 C. Pallotta, N.R de Tacconi and A.J. Arvia, Electrochim. Acta, 26 (1981) 261.

15 A.J. Arvia, Isr. J. Chem., 18 (1979) 89.

16 J.M.M. Droog. J. Electroanal. Chem., 115 (1980) 225.

17 R.H. Müller and C.G. Smith, Surf. Sci., 96 (1980) 375. 